\title{
Charles-Augustin Sainte-Beuve, Vie, poésies et pensées de Joseph Delorme
}

\section{Michel Brix}

\section{(2) OpenEdition}

1 Journals

\section{Édition électronique}

URL : https://journals.openedition.org/studifrancesi/30557

DOI : 10.4000/studifrancesi.30557

ISSN : 2421-5856

Éditeur

Rosenberg \& Sellier

\section{Édition imprimée}

Date de publication : 1 avril 2006

Pagination : 178-179

ISSN : 0039-2944

\section{Référence électronique}

Michel Brix, "Charles-Augustin Sainte-Beuve, Vie, poésies et pensées de Joseph Delorme », Studi Francesi [En ligne], 148 (XLX | I) | 2006, mis en ligne le 30 novembre 2015, consulté le 21 septembre 2021. URL : http://journals.openedition.org/studifrancesi/30557 ; DOI : https://doi.org/10.4000/ studifrancesi.30557

Ce document a été généré automatiquement le 21 septembre 2021.

\section{(c) $($ ) $\odot$}

Studi Francesi è distribuita con Licenza Creative Commons Attribuzione - Non commerciale - Non opere derivate 4.0 Internazionale. 


\title{
Charles-Augustin Sainte-Beuve, Vie, poésies et pensées de Joseph Delorme
}

\author{
Michel Brix
}

\section{RÉFÉRENCE}

CHARLES-AUGUSTIN SAINTE-BEUVE, Vie, poésies et pensées de Joseph Delorme, édition établie par JEAN-PIERRE BERTRAND et ANTHONY GLINOER, Paris, Bartillat, 2004, pp. 287.

1 On constate, depuis quelques années, que les débats ont repris sur Sainte-Beuve critique. Il ne faudrait pas, pour autant, oublier le poète et le romancier. Joseph Delorme a été peu lu au XXe siècle. La maison Bartillat vient d'avoir l'heureuse idée de le rééditer, et de confier cette entreprise à la compétence de Jean-Pierre Bertrand et d'Anthony Glinoer, qui nous proposent de redécouvrir le recueil de Sainte-Beuve en un volume maniable, agréable, bien présenté et bien documenté. La version choisie est celle des Poésies complètes de 1861 parues sous l'enseigne de Poulet-Malassis. C'est dans cette édition que Baudelaire lut, ou plutôt relut Delorme, qu'il qualifia en 1865, dans une formule fameuse, de «Fleurs du Mal de la veille». Les préfaciers nous rappellent aussi que, la même année, qui plus est dans un article sur Baudelaire, Verlaine ne fut pas moins élogieux que l'auteur du Spleen de Paris pour les vers de Sainte-Beuve.

2 Lorsqu'il parut, au début d'avril 1829, le recueil Vie, poésies et pensées de Joseph Delorme s'attachait à explorer, pour la poésie romantique, de nouvelles voies. À pareille date, Sainte-Beuve avait eu plusieurs fois déjà l'occasion de faire état de ses divergences esthétiques avec Hugo et Vigny, les figures les plus éminentes du Cénacle. Joseph Delorme conteste, à sa manière, les orientations contemporaines du romantisme. Le héros lui-même est une espèce d'anti-Hugo : mélancolique, éconduit dans ses amours, mal à l'aise en société, de santé précaire, solitaire, sortant peu, aspirant à la mort.

La discrétion qu'il affiche en art - et que Sainte-Beuve sous son masque revendique rompt avec les caractères $d u$ "grand chant romantique »: Joseph ne s'est «jamais essayé qu'en des peintures d'analyse sentimentale et des paysages de petite 
dimension » (p.57), mais il appartient tout de même, lui aussi, à l'école nouvelle. Et c'est à ce titre qu'il donne l'exemple, dans ses propres vers, d'une inspiration plus humble, plus familiale et quotidienne, d'une poésie d'intérieur, du foyer, de la simplicité, voire de la médiocrité acceptée. L'antagonisme apparaît notamment dans le poème intitulé «Ma Muse » (p.131-132), qui oppose à la muse hugolienne (représentée comme une "odalisque brillante») l'image d'une pauvre fille vivant dans une " chaumine » et lavant « un linge usé ». Cette image de faiblesse renvoie, non au talent intrinsèque de l'auteur, mais bien à l'inspiration qu'il a décidé de privilégier. Baudelaire ne procédera pas autrement, dans Les Fleurs du Mal, avec «La Muse malade » et « La Muse vénale ", sans que l'on infère, dans son cas à lui, que ces poèmes constituent des aveux d'échec. Justice devrait être rendue à Sainte-Beuve sur ce point. La discussion en tout cas peut s'engager, et chacun - grâce à cette nouvelle édition - pourra se prononcer en connaissance de cause. 